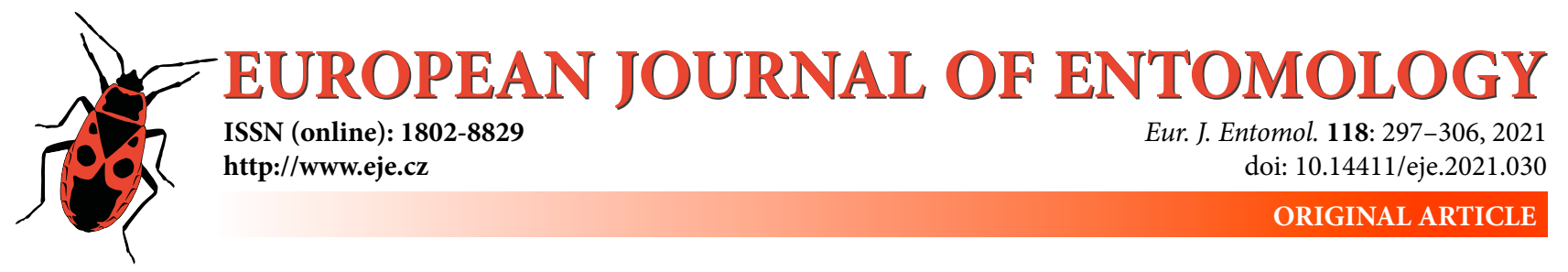

\title{
Effect of the energy content of diets on the development and quality of the fat reserves of larvae and reproduction of adults of the black soldier fly, Hermetia illucens (Diptera: Stratiomyidae)
}

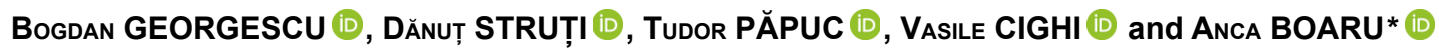 \\ Faculty of Animal Science and Biotechnologies, University of Agricultural Sciences and Veterinary Medicine Cluj-Napoca, \\ Calea Manastur 3-5, 400372 Cluj-Napoca, Cluj County, Romania; e-mails: georgescu.bogdan63@yahoo.com, \\ strutidanut@yahoo.com, ptudor2008@yahoo.com, vasile.cighi@usamvcluj.ro, boaruanca.usamvcluj@yahoo.com
}

Key words. Diptera, Stratiomyidae, Hermetia illucens, rearing diets, larva, fat-body, fatty acids, reproduction, egg clutch quality

Abstract. Hermetia illucens is a sustainable and an increasingly bioeconomical source of nutrients for farm animals. It is still necessary, however, to improve our knowledge of the biological features of this species in order to maximize its use. The aims of this research were to evaluate the effect of the energy level of rearing diets on its body weight and fat-body reserves. The quantity and quality of the fats storred by the non-feeding stages of this insect and its reproductive performances were also studied. A control $\operatorname{diet}(\mathrm{CD}-$ Gainesville diet) and three diets with progressively greater energy contents $(\mathrm{kcal} / \mathrm{kg} \mathrm{ME})$ were formulated. The increase was achieved by including different amounts of maize, 40\% (ED $), 60 \%\left(E D_{2}\right)$ and $80 \%\left(E D_{3}\right)$, in these three diets. Abother diet $\left(E D_{4}\right)$ consisted of fruit and vegetable waste. The results indicate that the body weight of larvae, prepupae, pupae and adult flies, as well as fat content of the larvae increased significantly $(p<0.01)$ with increase in the energy content of the diets. There was a positive Pearson correlation between energy content of diets and body weight of adult flies. The heaviest egg clutches with the highest number of eggs/clutch $(p<0.01)$ were laid by flies reared on the diets with the highest energy content. The quality of the fat stored by larvae did not influence the weight and number of egg laid.

\section{INTRODUCTION}

The black soldier fly Hermetia illucens L. is an edible insect of economic importance as it can be reared on a wide range of organic materials, including vegetable waste (Nguyen et al., 2013; Banks et al., 2014; Čičková et al., 2015; Wang \& Shelomi, 2017). Compared with other insect species, H. illucens is better at converting substrates into rich fertilizer (Nguyen et al., 2015; Oonincx et al., 2015; Boaru et al., 2018). Its chitin and derivatives have various uses in medical and pharmaceutical applications (Lalander et al., 2016). Moreover, H. illucens larvae are a valuable source of nutrition for farm animals, but their quality is dependent on the substrate they are reared on (St-Hilaire et al., 2007; Gobbi et al., 2013; Nguyen et al., 2015; Barroso et al., 2017; Pimentel et al., 2017; Danieli et al., 2019).

There are recent studies that show that the larvae of several insect species have a high body-fat content, along with proteins and other nutrients (Liu et al., 2017; Salomone et al., 2017; Cullere et al., 2019). Of the insects included in animal feed, Hermetia illucens is the richest in lipids (Makkar et al., 2014; Ramos-Bueno et al., 2016; Surendra et al., 2016). The fat content of the larvae and pupae is variable and up to $45 \%$ (Veldkamp \& Bosch, 2015; Ushakova et al., 2016; Barragan-Fonseca et al., 2017) and for these reasons, $H$. illucens is used for producing animal feed and biodiesel (Li et al., 2011; Surendra et al., 2016). Recently, the European Commission accepted Hermetia illucens for use as an alternative source of nutrients in aquaculture feeds (Regulation 2017/893/EC). The nutritional quality of $H$. illucens in terms of fatty acids is very variable and a large percentage are satturated (Ushakova et al., 2016; Barragan-Fonseca et al., 2017; Caligiani et al., 2018; Giannetto et al., 2020). There have been several attempts to manipulate the fatty acids profile by enriching their diets (Hoc et al., 2020; Truzzi et al., 2020). For example, the level of Omega-3 fatty acid in prepupae can be enhanced by feeding the larvae a diet containing fish offal (St-Hilaire et al., 2007), which makes them more suitable for feeding to fish (Magalhães et al., 2017; Renna et al., 2017).

From a physiological point of view, high amounts of lipids in $H$. illucens larvae provide energy for the non-feeding stages, especially reproduction (Li et al., 2011; Kroeckel et al., 2012; Nguyen et al., 2013). There is currently little

\footnotetext{
* Corresponding author; e-mail: boaruanca.usamvcluj@yahoo.com
} 
information on the acumulation, storage and metabolism of fats in H. illucens. Pimentel et al. (2017) demonstrate that the fat-body is an important organ in terms of metabolizing nutrients in VI-instar larvae as rearing them on a low protein level diet affects protein and lipid accumulation in fat-body cells and the expression of key genes involved in metabolic processes. Body-fats play a vital role in insect growth, development and reproduction, and are a source of energy during starvation (Pimentel et al., 2017). The nutrient content of $H$. illucens depends on its developmental stage (Liu et al., 2017), but the mechanisms involved are not clear. Studies conducted by Gianetto et al. (2020) suggest that the fatty acid profiles of the V-instar larvae and prepupae of this species may be related to the modulation of the expression of lipid metabolism genes during larval development and Zhu et al. (2019) have identified four metabolic genes that are associated with the accumulation of fat in larvae.

The energy (fat) available for each post feeding life stage has a direct effect on reproduction, with a positive correlation between fat deposits and eggs clutch quality (Georgescu et al., 2020). H. illucens is a good model for studying the accumulation nutrient reserves during larval development because the adult does not feed. Therefore, all the nutrients used in the adult stages rely on the reserves accumulated by larvae. Body-fats could be especially important for reproduction, but little is known about the role the fat-body in the life history traits of no-feeding stages H. illucens.

Thus, the aim of this research was to determine the effect of the energy content of larval rearing substrates on the amount of fat they accumulated, the influence of the quantity and quality of fat reserves in the development of no-feeding stages and its implications for reproduction.

\section{MATERIALS AND METHODS}

This research was carried out in the Ecology and Zoology Department of the University of Agricultural Sciences and Veterinary Medicine Cluj-Napoca (Romania) $\left(46^{\circ} 45^{\prime} 34.637^{\prime \prime} \mathrm{N}, 23^{\circ} 34^{\prime}\right.$ $1.969^{\prime \prime} \mathrm{E}, 365 \mathrm{~m}$ altitude).

\section{Origin of biological material}

The $H$. illucens came from a colony maintained year-round in an indoor laboratory $\left(27^{\circ} \mathrm{C} \pm 0.2\right.$ temperature and $65 \% \pm 3 \mathrm{RH}$ humidity) in the Ecology Environmental Protection and Zoology Laboratory of the above university. The initial material was purchased in 2017 from a farm in Greece. Each substrate was populated with one clutch of eggs weighing on average $19.0 \pm$ $0.4 \mathrm{mg}$ that were laid within $24 \mathrm{~h}$ of the adult $H$. illucens females emerging.

\section{Experimental design}

All the H. illucens larvae from each clutch were reared on one of five diets, the composition and nutritional value is presented in Table 1. The Geinesweile diet (Hogsette, 1992) was the control diet (CD). Three other diets, contained the same amount of protein, but the energy content ( $\mathrm{kcal} / \mathrm{kg} \mathrm{ME})$ was increased by including different percentages of maize flour: $40 \%\left(\mathrm{ED}_{1}\right), 60 \%$ $\left(\mathrm{ED}_{2}\right)$ and $80 \%\left(\mathrm{ED}_{3}\right)$. In addition, diet $\left(\mathrm{ED}_{4}\right)$ consisted of fruit and vegetable waste, similar to the natural food of H. illucens (Table 1).

The experiment started when the egg clutches were placed on the rearing substrates, which were prepared under the following conditions: $70 \% \pm 2 \%$ humidity and $26 \pm 0.4^{\circ} \mathrm{C}$ (Sheppard et al., 2002). Larvae hatched approximately $72 \mathrm{~h}$ later when kept under the following conditions: $27^{\circ} \mathrm{C} \pm 0.2$ and $65 \% \pm 3 \mathrm{RH}$ (Tomberlin et al., 2009; Holmes et al., 2012; Hoc et al., 2019). Recently hatched maggots were reared on each of the diets. The larvae were reared in separate $50 \times 34 \times 14 \mathrm{~cm}$ plastic containers. After 20-21 days prepupae started to develop except for those reared on organic waste $\left(\mathrm{ED}_{4}\right)$ where they developed later, at the age of 29-31 days.

The prepupal and pupal stages of each group of $H$. illucens were kept on a dry leaf substrate in the dark in a $15 \times 10 \times 5 \mathrm{~cm}$ box, with an air hole, at $27^{\circ} \mathrm{C} \pm 0.2$ and $65 \% \pm 3 \mathrm{RH}$. H. illucens flies of each weight category were kept in cages measuring 50 $\times 35 \times 45 \mathrm{~cm}$ at $27^{\circ} \mathrm{C} \pm 0.1$ and $65 \% \pm 2 \mathrm{RH}$ (Park et al., 2010; Nakamura et al., 2016). Each of these cages contained a plastic box (dimensions $20 \times 15 \times 10 \mathrm{~cm}$ ) containing a substrate for laying eggs, consisting of a mixture of $50 \%$ wheat bran, $30 \%$ alfalfa meal and 20\% maize meal (Hogsette, 1992). The box containing the substrate was covered with mosquito mesh and an oviposition support consisting of ten pieces of wood with gaps of 2-3 $\mathrm{mm}$ between them (Boaru et al., 2019). The wooden support was replaced daily with a new sterilized support. The photoperiod the flies were exposed to was $8 \mathrm{~h}$ of dark and $16 \mathrm{~h}$ of yellow and white light from LEDs (Nakamura et al., 2016).

Table 1. The composition and nutritional value of the diets.

\begin{tabular}{lccccc}
\hline \multirow{2}{*}{ Ingredients (\%) } & \multirow{2}{*}{$\mathrm{CD}$} & \multicolumn{4}{c}{ Dietary treatments } \\
\cline { 3 - 6 } & & $\mathrm{ED}_{1}$ & $\mathrm{ED}_{2}$ & $\mathrm{ED}_{3}$ & $\mathrm{ED}_{4}$ \\
\hline Maize & 20 & 40 & 60 & 80 & - \\
Wheat bran & 50 & 35 & 20 & 3 & - \\
Alfalfa meal & 30 & 20.7 & 11.4 & 4 & - \\
Soybean meal & - & 4.3 & 8.6 & 13 & - \\
Fruit and vegetable waste & - & - & - & - & 100 \\
TOTAL & 100 & 100 & 100 & 100 & 100 \\
\hline Nutritional value & & & & & \\
Dry matter (DM) & 87.90 & 87.66 & 87.43 & 87.22 & - \\
Crude protein (\%) & 13.55 & 13.54 & 13.53 & 13.56 & $11.9-20^{1}$ \\
Crude fat (\%) & 3.46 & 3.28 & 3.09 & 2.89 & $2.6-1.5^{1}$ \\
Crude fiber (\%) & 13.30 & 10.02 & 6.75 & 3.69 & - \\
Metabolizable energy (kcal/kg) & 1737.90 & 2174.50 & 2611.09 & 3044.53 & $3607-3718^{1}$ \\
\hline
\end{tabular}

${ }^{1}$ Data of Nguyen et al. (2015) and Meneguz et al. (2018); CD - control diet (Gainesville Diet); ED 1 - diet with 40\% maize; $\mathrm{ED}_{2}$ - diet with $60 \%$ maize; $\mathrm{ED}_{3}$ - diet with $80 \%$ maize; $\mathrm{ED}_{4}$ - diet ofg fruit and vegetable waste. 
Table 2. Mean body weight (mg) of Hermetia illucens at different stages in its development when reared on the different diets.

\begin{tabular}{|c|c|c|c|c|c|c|c|c|}
\hline \multirow{2}{*}{ Development stage } & \multirow{2}{*}{$\begin{array}{c}\text { CD } \\
\bar{x} \pm \mathrm{sd}\end{array}$} & \multirow{2}{*}{$\begin{array}{c}E D_{1} \\
\bar{x} \pm s d\end{array}$} & \multirow{2}{*}{$\begin{array}{c}E_{2} \\
\bar{x} \pm s d \\
\end{array}$} & \multirow{2}{*}{$\begin{array}{c}\mathrm{ED}_{3} \\
\overline{\mathrm{x}} \pm \mathrm{sd}\end{array}$} & \multirow{2}{*}{$\begin{array}{c}\mathrm{ED}_{4} \\
\overline{\mathrm{x}} \pm \mathrm{sd}\end{array}$} & \multicolumn{3}{|c|}{ Anova-single way } \\
\hline & & & & & & Df & $\mathrm{F}$ & P-value \\
\hline Larvae 10 -days old $(n=50)$ & $142.47 \pm 22.47^{a}$ & $162.44 \pm 21.49^{b}$ & $164.70 \pm 14.82^{\mathrm{b}}$ & $172.88 \pm 14.54^{b}$ & $104.60 \pm 22.14^{c}$ & 4 & 99.67 & 0.000 \\
\hline Larvae 15-days old $(n=50)$ & $239.74 \pm 19.46^{a}$ & $273.66 \pm 32.04^{b}$ & $293.36 \pm 31.72^{c}$ & $301.61 \pm 33.33^{c}$ & $167.50 \pm 42.51^{d}$ & 4 & 139.34 & 0.000 \\
\hline Larvae 20 -days old $(n=50)$ & $241.80 \pm 43.68^{a}$ & $276.39 \pm 36.50^{b}$ & $298.15 \pm 27.58^{c}$ & $313.13 \pm 35.68^{c}$ & $243.22 \pm 27.26^{\mathrm{ad}}$ & 4 & 40.33 & 0.000 \\
\hline Prepupae $(n=50)$ & $153.00 \pm 27.10^{a}$ & $181.59 \pm 35.70^{b}$ & $193.89 \pm 33.10^{\mathrm{bc}}$ & $201.77 \pm 32.7^{c}$ & $229.75 \pm 28.20^{d}$ & 4 & 29.29 & 0.000 \\
\hline Pupae $(n=50)$ & $135.48 \pm 24.90^{a}$ & $159.88 \pm 28.70^{b}$ & $163.56 \pm 32.10^{b}$ & $174.18 \pm 27.90^{b}$ & $206.44 \pm 30.40^{c}$ & 4 & 40.13 & 0.000 \\
\hline Imago $(M+F)(N=100)$ & $22.25 \pm 7.10^{a}$ & $27.60 \pm 8.70^{\mathrm{b}}$ & $34.66 \pm 9.50^{\mathrm{bc}}$ & $39.27 \pm 10.60^{d}$ & $51.95 \pm 16.80^{e}$ & 4 & 107.10 & 0.000 \\
\hline
\end{tabular}

Different letters between columns indicate significant differences at $5 \%$ using Tukey-test as a post hoc test; $\bar{x} \pm$ sd - mean \pm standard deviation; CD - control diet; $\mathrm{ED}_{1}-\mathrm{ED}_{4}$ - other diets.

\section{Parameters recorded}

The following parameters were monitored and recorded: (1) the body weights of the larvae, prepupae, pupae and adults reared on diets that differed in their energy contents; (2) fat content and the fatty acid profile of the fats of the larvae; (3) the effect of the different rearing diets on the flies reproductive parameters and quality of the eggs clutches.

The body weights of 50 larvae randomly collected from each diet were recorded when they were 10, 15 and 20 days old. When the prepupae left the substrate, their weight was also determined $(\mathrm{N}=50)$ as was that of the pupal stage $(\mathrm{N}=50)$. For the adults, the weight of the egg clutches, the number of eggs in each clutch and the weight of an egg were recorded for each experimental group. The weight of the adults was assessed when exitus occured and individuals were randomly selected and sexed $(\mathrm{N}=50$ for each sex).

Individuals at various stages of development were weighed using an analytical balance (accuracy $0.01 \mathrm{mg}$ ). The eggs in the clutches were separated from one another by immersing the clutches in $70 \%$ ethanol (Nakamura et al., 2016) followed by photographing them under a binocular magnifier Alpha model (zoom $7 \times-45 \times$ ) and counting them using counting software.

\section{Fat content and fatty acids analysis}

The fat content of larvae 10 and 20 days old was determined using the procedures established by AOAC International (2005), the dry matter (method no. 934.01) and the crude fat content were determined using the Soxhlet method (method no. 920.39).

The lipid fatty acids in 20-day-old larvae were determined. Ten grams of larvae were collected from each substrate, placed for $24 \mathrm{~h}$ on a dry substrate for them to defecate, washed of impurities with disitilated water, then stored at $-80^{\circ} \mathrm{C}$ in a freezer until the chemical analyses. The extraction and identification of fatty acid methyl esters (FAME) in Hermetia illucens larvae was done using gas chromatography and mass spectrometry, in accordance with AOAC-969.33 (AOAC, 1995) and ISO 3657: 2002, ISO 12966-2: 2011, ISO 12966-2: 2017. Identification and quantification of fatty acid methyl esters (FAME) involved saponification of lipids using a methanolic sodium hydroxide solution 0.5 $\mathrm{mol} / \mathrm{L}$, followed by esterification using a boron trifluoride catalyst $15 \%$ vol. and adding hexane after cooling. The equipment used was a Perkin Elmer Chromatographic system with mass spectrometer detector (GC-MS) with a Clarus 680 gas chromatograph (with programmable injector and thermostat oven) and Clarus SQ8T quadrupole mass spectrometer. Equipment consisted of an Elite-Wax chromatographic column with stationary polar phase Polyethylene glycol (PEG), length $30 \mathrm{~m}$, internal diameter $0.25 \mathrm{~mm}$ and film thickness of $1.0 \mu \mathrm{m}$; injection port temperature of $220^{\circ} \mathrm{C}$, injected sample volume $1.0 \mu \mathrm{l}$, helium carrier gas rate of flow $1.5 \mathrm{ml} / \mathrm{min}$, splitting ratio $40: 1$. The operating conditions of MS were: transfer line temperature $150^{\circ} \mathrm{C}$; source temperature $150^{\circ} \mathrm{C}$; multiplier 1500 ; solvent delay $0-1.5 \mathrm{~min}$. The determina- tion of fatty acid concentrations in the analysed samples was done by comparing the relative retention time of FAME with that of a certified standard (Mix FAME Supelco 37). The individual fatty acid concentrations are expressed in $\mathrm{mg} / \mathrm{g}$ of larval fat.

\section{Statistical analysis}

Data were analyzed using Microsoft Excel 2010. Difference between groups were tested by one-way ANOVA using Tukey HSD as a post hoc test for comparison with 5\% and 1\% significance levels, as well as in the case of egg clutches, difference analysis. Corelations were based on Pearson coefficients. All data is presentend as a mean $\pm \mathrm{SD}$ (standard deviation).

\section{RESULTS}

\section{Parameters of the development of the different stages of $\boldsymbol{H}$. illucens}

Body weights of larvae, prepupae, pupae and adults reared on the different diets are presented in Table 2 . There is a significant increase $(\mathrm{p}<0.01)$ in body weight with increase in the energy content of the diet for each larval stage (Table 2). This aspect is also confirmed by the significant Pearson correlation coefficients $(r=0.935 ; r=0.983)$ of the relationships between the weight of the larvae and energy content of the rearing diet (Table 5). No significant differences $(p>0.05)$ were found between the weights of the larvae reared on diets $\mathrm{ED}_{2}$ and $\mathrm{ED}_{3}$. In the case of the $\mathrm{ED}_{4}$ diet, the body weight of the larvae is lower than on the other diets up to the age of 20 days, but slightly higher than the weight of the larvae reared on CD (Table 2).

With increase in age larvae increase in body weight similarly in each experimental group (Fig. 1).

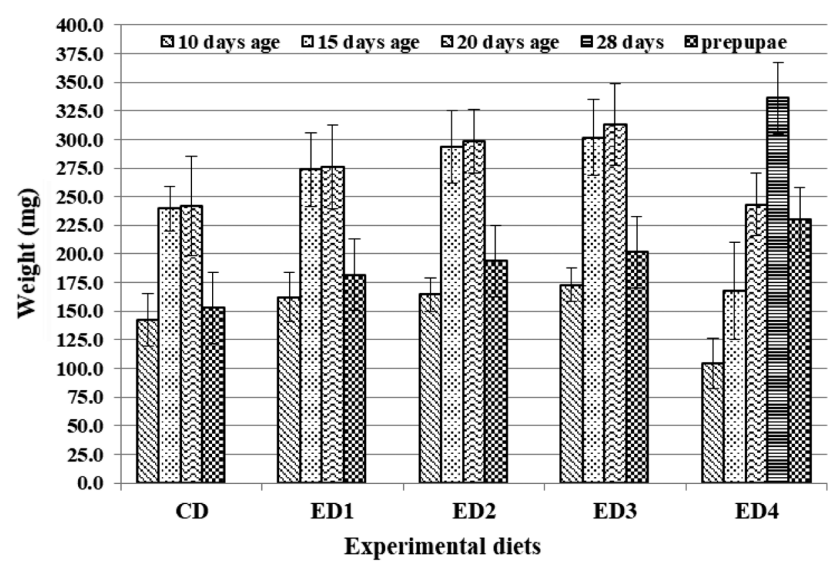

Fig.1. The body weight of $H$. illucens at different stages in its development when reared on the different diets $\left(C D-E D_{4}\right)$. 
Table 3. Fatty acid content of the fat in 20-day-old larvae of the black soldier fly reared on different diets ( $\mathrm{mg} / \mathrm{g}$ fat).

\begin{tabular}{|c|c|c|c|c|c|}
\hline Fatty acids $(\mathrm{mg} / \mathrm{g})(\mathrm{n}=3)$ & $\mathrm{CD}$ & $\mathrm{ED}_{1}$ & $\mathrm{ED}_{2}$ & $\mathrm{ED}_{3}$ & $\mathrm{ED}_{4}$ \\
\hline Miristic acid (C14:0) & 9.64 & 9.63 & 9.76 & 9.88 & 9.69 \\
\hline $6: 0)$ & 179.54 & 102.42 & 139.65 & 197.88 & 160.32 \\
\hline$d(C 18: 0)$ & 38.20 & 27.81 & 35.34 & 51.73 & 42.59 \\
\hline (C16:1) & 62.40 & 32.56 & 46.49 & 65.56 & 33.07 \\
\hline & 96 & 47.71 & 65.77 & 90.30 & 74.37 \\
\hline i-6) & 42.58 & 85.82 & 129.95 & 184.86 & 85.8 \\
\hline & 4.26 & 6.39 & 8.94 & 10.51 & 12.16 \\
\hline & 227.38 & 139.86 & 184.75 & 259.49 & 212.6 \\
\hline & 178.20 & 172.48 & 251.15 & 351.23 & 205.4 \\
\hline & .36 & 80.27 & 112.26 & 155.86 & 107.44 \\
\hline & 84 & 92.21 & 138.89 & 195.37 & 97.96 \\
\hline & & 1.23 & 1.36 & 1.35 & 0.97 \\
\hline & 0.21 & 0.66 & 0.75 & 0.75 & 0.46 \\
\hline MUFA / SFA & 0.58 & 0.57 & 0.61 & 0.60 & 0.51 \\
\hline
\end{tabular}

${ }^{*} \Sigma$ SFA - sum of satturated fatty acids; $\Sigma$ UFA - sum of unsatturated fatty acids; $\Sigma$ MUFA - sum of monounsatturated fatty acids; IPUFA - sum of polyunsatturated fatty acids; CD - control diet; $\mathrm{ED}_{1}-\mathrm{ED}_{4}-$ other diets.

The change in weight of the larvae from one age group to another is significant for those reared on $\mathrm{CD}(\mathrm{F}=173.12$; $\mathrm{df}=2 ; \mathrm{P}=0.000), \mathrm{ED}_{1}(\mathrm{~F}=224.78 ; \mathrm{df}=2 ; \mathrm{P}=0.000) \mathrm{ED}_{3}$ $(\mathrm{F}=432.75 ; \mathrm{df}=2 ; \mathrm{P}=0.000)$ and $\mathrm{ED}_{4}(\mathrm{~F}=350.40 ; \mathrm{df}=$ $2 ; \mathrm{P}=0.000)$. The greatest increase in body weight was recorded between day 1 and $15(\mathrm{p}<0.01)$. In particular, in the $\mathrm{ED}_{4}$ group the significant increase in weight $(\mathrm{p}<0.01)$ continues up to 28 days, because in this group duration of the larval stage was longer. In the other groups, there were no significant increases $(p>0.05)$ in weight between 15 and 20 days (Fig. 1).

The weight of the prepupal stage of Hermetia ilucens was significantly $(\mathrm{p}<0.01)$ lower than that of the larval stage prior to the prepupal stage (Fig. 1). The prepupal weight differed significantly $(\mathrm{p}<0.01)$ in the different treatments (Table 2). The weight of the CD prepupae was significantly lower $(\mathrm{p}<0.05)$ than that of those reared on the other diets. The weight of the $\mathrm{DE}_{4}$ prepupae was significantly greater $(p<0.05)$ than that of those reared on the other diets (Table 2).

The weights of the pupae were significantly lower $(p<0.01)$ than that of the pre-pupae reared on all the diets. The differences between the weights of the pupae reared on the different diets are significant $(\mathrm{F}=40.13 ; \mathrm{df}=4 ; \mathrm{P}=$ $0.000)$ with those reared on $\mathrm{ED}_{4}$ the heaviest $(\mathrm{p}<0.01)$ and on $\mathrm{CD}$ the lightest $(\mathrm{p}<0.01)$ (Table 2$)$.

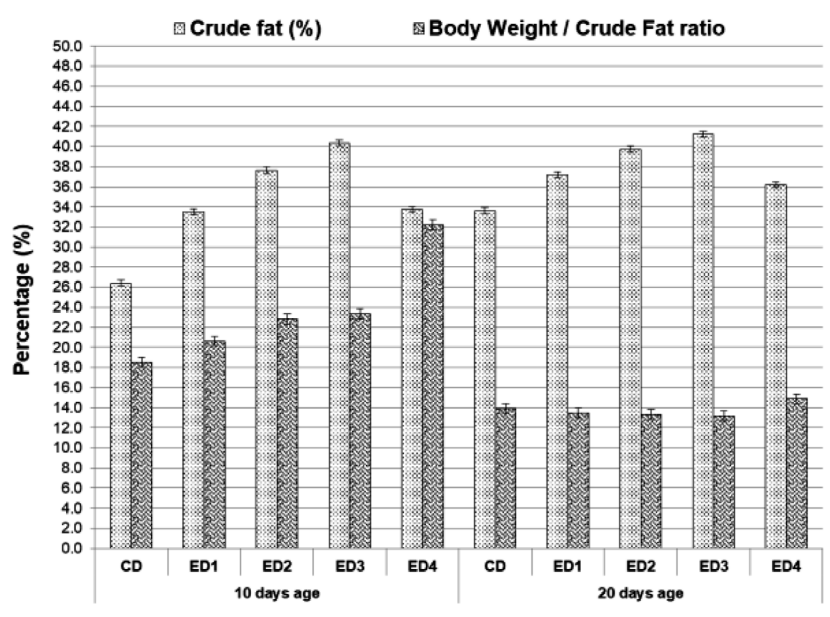

Fig. 2. Fat content (\%) and the amount of fat per unit body mass of 10 and 20 -day-old larvae reared on the different diets $\left(C D-E D_{4}\right)$.

The weights of the adults reared on the different diets differed significantly $(\mathrm{p}<0.01)(\mathrm{F}=107.1$; df $=4 ; \mathrm{P}=$ $0.000)$. Only those reared on $\mathrm{ED}_{1}$ and $\mathrm{ED}_{2}$ were similar in weight $(p>0.05)$. The weights of the females on the diets with the highest energy contents were significantly greater $(p<0.01)$ than that of those reared on the other diets (Table 4). The differences in the weights of the males reared on the different diets were similarly significant $(p<0.01)$, except for $\mathrm{ED}_{2}$ and $\mathrm{ED}_{3}(\mathrm{p}>0.05)$ (Table 4). The data confirm that the weights of females and males differ significantly $(p<0.01)$. The lifespan of adults reared on the different diets did not differ significantly $(p>0.05)$, being $8-11$ days.

\section{Fat content of larvae}

The higher energy content of rearing diets lead to the higher crude fat $(\mathrm{CF} \%)$ content of the larvae at all stages in their development (Pearson correlations: $r=0.976 ; r=$ 0.986) (Fig. 2). The CF content of 10-day old larvae was less than that of 20-day old larvae (Fig. 2). The highest fat content was recorded for $\mathrm{ED}_{3}$ larvae both at 10 days (40.34\%) and 20 days (41.21\%), followed by $\mathrm{ED}_{2}$ larvae. The lowest CF was recorded for CD larvae, regardless of their age (26.4-33.6\%) (Fig. 2).

The $\mathrm{ED}_{4}$ 10-day old larvae contained the highest ratio of body mass/fat content (32.23\%) (Fig. 2), followed by those of $\mathrm{ED}_{3}$. That of the other groups decreases linearly with the energy contents of the diets and was between 23.34$18.53 \%$ (Fig. 2). This ratio for 20-day old larvae was also

Table 4. Mean weights of adult individuals (male, female), clutches of eggs and individual eggs, and the mean number of eggs per clutch (as a mean), the larvae of which were reared on different diets (CD-ED ${ }_{4}$ ).

\begin{tabular}{|c|c|c|c|c|c|c|c|c|}
\hline \multirow{2}{*}{ Specification } & \multirow{2}{*}{$\begin{array}{c}C D \\
\bar{x} \pm s d\end{array}$} & \multirow{2}{*}{$\begin{array}{c}\mathrm{ED}_{1} \\
\overline{\mathrm{x}} \pm \mathrm{sd}\end{array}$} & \multirow{2}{*}{$\begin{array}{c}\mathrm{ED}_{2} \\
\overline{\mathrm{x}} \pm \mathrm{sd}\end{array}$} & \multirow{2}{*}{$\begin{array}{c}\mathrm{ED}_{3} \\
\overline{\mathrm{x}} \pm \mathrm{sd}\end{array}$} & \multirow{2}{*}{$\begin{array}{c}\mathrm{ED}_{4} \\
\overline{\mathrm{x}} \pm \mathrm{sd}\end{array}$} & \multicolumn{3}{|c|}{ Anova single-way } \\
\hline & & & & & & Df & $\mathrm{F}$ & $P$ \\
\hline & $0.28 \pm 6.2^{a}$ & $23.41 \pm 4.8^{b}$ & $9.86 \pm 6.9$ & $1.36 \pm 5.5^{c}$ & $.70 \pm 16.2^{\mathrm{d}}$ & 4 & 1.45 & 0.000 \\
\hline 50) & & & 3 & $3^{d}$ & $3^{e}$ & 4 & .57 & 0.000 \\
\hline & & & & & & 4 & & 0.000 \\
\hline & & $3.1^{b}$ & 102 & 105 & & 4 & 32.54 & 0.000 \\
\hline Egg weight ( $\mathrm{n}$ & $0.0229 \pm 0.1^{a}$ & $0.0221 \pm 0.1^{a}$ & $0.0220 \pm 0.1^{a}$ & $0.0227 \pm 0.1^{a}$ & $0.0184 \pm 0.1^{b}$ & 4 & 4.45 & 0.004 \\
\hline
\end{tabular}

Different letters between columns indicate significant differences at $5 \%$ using the Tukey-test as a post hoc test; $\bar{x} \pm \mathrm{sd}-$ mean \pm standard deviation; $\mathrm{CD}$ - control diet; $\mathrm{ED}_{1}-\mathrm{ED}_{4}$ - other diets. 
highest for the $\mathrm{ED}_{4}$ group (14.87\%) with that of the other groups approximately equal (13.16-13.90\%) (Fig. 2).

The fat content and fatty acid profile of the fat of 20-dayold larvae, is very dependent on the diet (Table 5). The highest level of saturated fatty acids (SFA) in larvae was recorded for $\mathrm{ED}_{3}$. In addition, this group also has the highest level of unsaturated fatty acids (UFA), which also reflects the high UFA content of this diet (ensured by soybean meal).

Of the saturated fatty acids, palmitic acid (C16: 0) was quantitatively higher in the fat of larvae reared on $\mathrm{ED}_{3}$ $(197.88 \mathrm{mg} / \mathrm{g})$. In the fat of larvae reared on $\mathrm{ED}_{4}$, approximately equal amounts of SFA and UFA (212.6 vs 205.4 $\mathrm{mg} / \mathrm{g}$ ) were recorded. The UFA/SFA value decreased from 1.36 to 0.78 in the larvae reared on diets in which the proportion of unsaturated fatty acids (UFA) was least (Table 3).

The highest concentration of linoleic acid (C18: 2 n-6) was recorded in the fat of larvae reared on $\mathrm{ED}_{3}$, which contains the highest level of soybean meal and the concentrations in the larvae reared on the other diets decreased as the proportion of soybean meal in the diet decreased. This is also reflected in the degree of fat polyunsaturation (PUFA/ SFA), being highest in the groups where the amount of soybean meal in the diet was highest $\left(0.75\right.$ in $\mathrm{ED}_{2}$ and $\left.\mathrm{ED}_{3}\right)$ (Table 3).

Concentration of monounsaturated fatty acids (MUFA), such as, oleic acid (C18: 1 cis-9), also depended on their concentrations in the diets, with $47.7 \mathrm{mg} / \mathrm{g}\left(\mathrm{ED}_{1}\right)$ and 90.3 $\mathrm{mg} / \mathrm{g}\left(\mathrm{ED}_{3}\right)$ (Table 3).

\section{Egg clutches}

The weight of the clutches of eggs laid by the flies reared on $\mathrm{CD}$ is significantly lower $(\mathrm{p}<0.05)$ than that of those reared on $\mathrm{ED}_{3}$ and $\mathrm{ED}_{4}$ (Table 4). The flies reared on $\mathrm{ED}_{4}$ laid the heaviest clutches and the highest number of eggs per clutch $(p<0.01)$. However, the weights of individual eggs laid by these adults was significantly lower $(p<0.05)$ than those laid by adults reared on the other diets, between which the differences were insignificant $(p>0.05)$ (Table 4).

The above relationships are supported by the positive coefficients of the Pearson correlations between the weight of a clutch of eggs and number of eggs per clutch, and the energy contents of the diets, as well as with the fat reserves of larvae (Table 5).

\section{DISCUSSION}

\section{Effect of the energy content of the diet on the growth and development of $\boldsymbol{H}$. illucens}

The greater the energy content of a rearing diet the heavier the $H$. illucens reared on that diet $(\mathrm{p}<0.01)$. Up to the age of 10 days, larval growth on all diets was similar, indicating an intense metabolism. Individuals from $\mathrm{ED}_{4}$ diet had a higher body weight $(\mathrm{p}<0.01)$ before the prepupal stage, which corresponds to a larval age of 28 days (Fig. 1). The lower body weights of the early larval stages of individuals reared on $\mathrm{ED}_{4}$, which increase greatly the latter phase of growth is also mentioned by Jucker et al. (2017). Our results confirm that the duration of larval development was significantly longer $(p<0.05)$ on the diet composed of mixed fruits and vegetables than on the other diets. Other studies indicate that, on this type of substrate, the duration of larval development can be up to 30 days (Meneguz et al., 2018) or even longer (Jucker et al., 2017). Similarly, Srikanth \& Sharanabasappa (2021) report that the duration of larval development when reared on different fruits and vegetables is 28-29 days. For this species, fruit and vegetable substrates are their natural source of food and the one to which it is optimally adapted (Tomberlin \& Sheppard, 2002). This is supported by our results that indicate the growth and development processes are uniform throughout the larval stages, which increase in weight right up to the prepupal stage. Meneguz et al. (2018) report that there are no significant differences between the weight of the larvae reared on particular fruit and vegetable substrates. The weight of the larvae reared on $\mathrm{ED}_{4}$ is higher than that previously reported by Jucker et al. (2017) (154.0 mg),

Table 5. Pearson correlation coefficients of the relationships between the different features of $H$. illucens $(\mathrm{N}=8)$ monitored and the energy contents of their diets.

\begin{tabular}{|c|c|c|c|}
\hline \multirow{2}{*}{$\begin{array}{c}\text { Correlation } \\
\text { number }\end{array}$} & \multicolumn{2}{|c|}{ Interactions } & \multirow{2}{*}{ Pearson coeficient $(r)$} \\
\hline & Factor A & Factor B & \\
\hline 1 & Weight of 10-day-old larvae & \multirow{9}{*}{ Metabolisable energy in diets } & $0.935^{\star * *}$ \\
\hline 2 & Weight of 20-day-old larvae & & $0.983^{* * *}$ \\
\hline 3 & Fat content of 10-day-old larvae & & $0.976^{* * *}$ \\
\hline 4 & Fat content of 20-day-old larvae & & $0.986^{* * *}$ \\
\hline 5 & Prepupal weight & & $0.890^{\star *}$ \\
\hline 6 & Pupal weight & & $0.974^{* * *}$ \\
\hline 7 & Male imago weight & & $0.996^{* * *}$ \\
\hline 8 & Female imago weight & & $0.927^{* * *}$ \\
\hline 9 & Weight of a clutch of eggs & & $0.989^{* * *}$ \\
\hline 10 & Weight of a 10-day-old larvae & \multirow{3}{*}{ Fat content of larvae 10 -days old } & $0.874^{* \star}$ \\
\hline 11 & Weight of a clutch of eggs & & $0.887^{* *}$ \\
\hline 12 & Number of eggs in a clutch & & $0.776^{*}$ \\
\hline 13 & Weight of 20-day-old larvae & \multirow{3}{*}{ Fat content of larvae 20-days old } & $0.949^{* * *}$ \\
\hline 14 & Weight of a clutch of eggs & & $0.982^{* * *}$ \\
\hline 15 & Number of eggs in a clutch & & $0.932^{* * *}$ \\
\hline
\end{tabular}

Significance: * significant difference; ${ }^{* *}$ very significant differences; ${ }^{* * *}$ highly significant differences. 

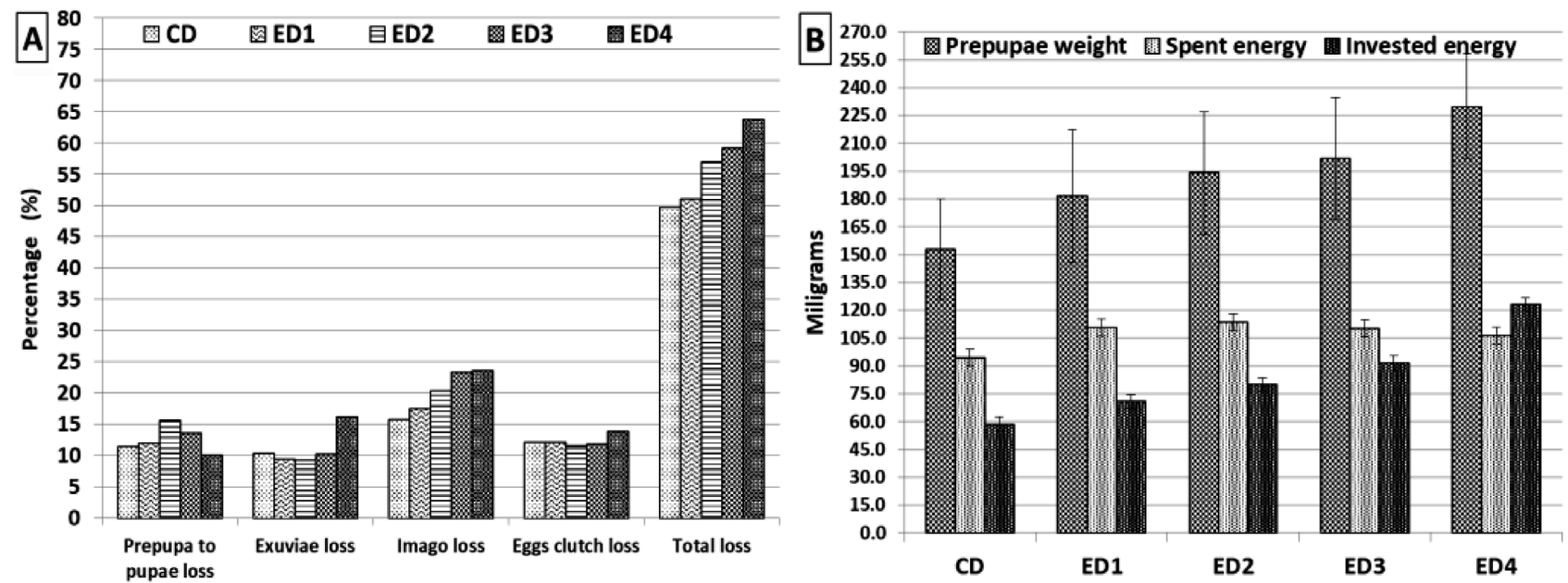

Fig. 3. A - Percentage loss of body weight by the non-feeding stages of Hermetia illucens (relative to the initial weight of the prepupae) reared on the different diets $\left(C D-E D_{4}\right)$. B - Relative amounts of the initial mass of prepupae dissipated and invested in reproduction when reared on each of the diets $\left(C D-E_{4}\right)$ (spent energy = prepupal weight - weight of exuviae - weight of imago - weight of egg clutch; Invested energy $=$ weight of exuviae + weight of imago + weight of egg clutch).

Meneguz et al. (2018) and Bruno et al. (2019). Recently, Srikanth \& Sharanabasappa (2021) report that the mean weights of last instar larvae, reared on particular fruit and vegetable substrates, is $0.18 \mathrm{~g}$ and $0.17 \mathrm{~g}$, which is lower than the $0.33 \mathrm{~g}$ we recorded (Fig. 1).

The larval weight recorded for the Gainesville diet $(241.8 \mathrm{mg}$ ) is greater than that previously reported by Harden \& Tomberlin (2016) (178.4 mg) and Miranda et al. (2020) (175-200.0 mg). However, it is close to the weights reported by Jucker et al. (2019) $(235.0 \mathrm{mg})$ and Bruno et al. (2019) $(218.0 \mathrm{mg}$ ). The effect of the quality of the substrate on larval body weight is is reported in other studies (Nguyen et al., 2015; Jucker et al., 2017; Wang \& Shelomi, 2017; Barragan-Fonseca et al., 2018). Thus, Bava et al. (2019) report a higher larval weight $(229.0 \mathrm{mg})$ when reared on a substrate with a protein content of $17.0 \%$ and fat content of $4.0 \%$ than on a substrate with a higher protein content (39.2\%) and similar fat content (17.2\%) (197.0 $\mathrm{mg}$ larval weight). These authors conclude that a high nutritional value of the rearing diet does not necessarily result in heavier individuals. The findings of Cammack \& Tomberlin (2017) indicate that protein and carbohydrates in a ratio of $1: 1$ and a $70 \%$ substrate humidity are optimal for larval development and a lower consumption food.

The duration of larval development on diets, other than Gainesville and mixed fruit and vegetables, is between 15.8 and 26.8 days (Barragan-Fonseca et al., 2018), which is similar to the durations of the larval development recorded on the $\mathrm{ED}_{1}-\mathrm{ED}_{3}$ diets.

The duration of the prepupal stage was not significantly affected $(p>0.05)$ by the energy contents of the diets. The weights of the prepupae reared on the different diets differed significantly $(p<0.01)$. The lightest prepupae were those reared on the control diet $(153.0 \pm 27.1 \mathrm{mg})$ and heaviest those reared on $\mathrm{ED}_{4}(229.75 \pm 28.2 \mathrm{mg})$. The weights of the prepupae reflect the energy contents of the diets they were reared on (Pearson $r=0.890)$ (Table 5). The prepupal weights recorded in this study are higher than those reported by Cammack \& Tomberlin (2017) and Miranda et al. (2020) (170-180 mg) for prepupae reared on the same type of substrate (Gainesville diet). Hoc et al. (2020) report prepupal weights for larvae reared on a poultry feed (200.04-251.16 mg), which are comparable to those record in the present research on the control diet $(241.8 \mathrm{mg})$.

The pupal weights reflect the differences $(\mathrm{p}<0.01)$ in those of the previous stages of $H$. illucens, with those reared-on diets with high energy contents having the higher pupal weights (Pearson $r=0.974$ ). The pupal weight recorded for the $\mathrm{ED}_{4}$ diet is higher than that for the other diets (Table 2). Comparable values are reported by Jucker et al. (2019) for pupae, from larvae reared on the standard diet $(142.0 \mathrm{mg})$. Shrikanth \& Sharanabasappa (2021) report that pupae developing from larvae reared on vegetable and fruit substrates have a mean weight close to those we recorded for $\mathrm{ED}_{4}(0.17$ and 0.16 vs. $0.20 \mathrm{~g} /$ pupae $)$.

The difference in the weights of the flies was $(p<0.01)$ correlated with the energy content of the rearing substrates (Pearson $r=0.927-0.996)$. Thus, the lowest weight was recorded for the control and the highest for $\mathrm{ED}_{4}$ (Table 2). Jucker et al. (2020) report comparable weights for males $(27.2 \mathrm{mg})$ and females $(32.4 \mathrm{mg})$. Our results confirm that females are heavier than males. The lifespan of flies was 8-11 days, which overlaps that reported by Miranda et al. (2019), who report 4.7-8.2 days and Heussler et al. (2018) 4-15 days.

\section{Importance of fat accumulated by larvae for subsequent development}

Body weight loss in post-feeding stages of Hermetia illucens is due to the stored fat being used exclusively for reproduction, which is entirely dependent on the energy reserves (fat-body) accumulated during the larval period. These losses increase with increase in body weight (Fig. $3 \mathrm{~A}$ ) and are associated with costs of the metabolic processes associated with metamorphosis. However, the heaviest adults invested the most energy in egg clutches (Fig. 3A). On diets $\mathrm{CD}-\mathrm{ED}_{3}$, the body mass losses associated with 


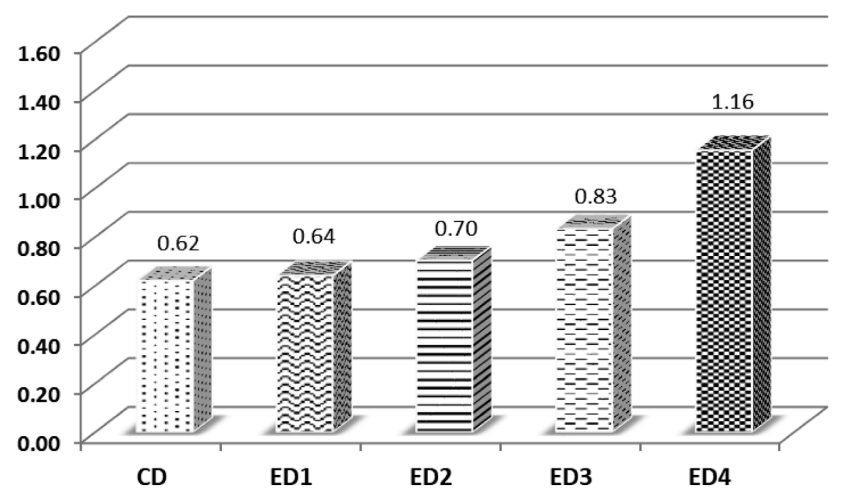

Fig. 4. Available energy reproductive conversion index according to diets $\left(\mathrm{CD}-\mathrm{ED}_{4}\right)$.

metamorphosis is greater than that associated with producing egg clutches (Fig. 3B). Only in $\mathrm{ED}_{4}$ was the energy dissipated lower than the energy invested, possibly due to their adaptation to this type of food (fruit and vegetables), which results in a higher final energy reserve for investing in reproduction and oviposition (Fig. 3B).

The ratio between energy invested in exuviae, imago dead and egg clutches and energy losses due to development of the post-feeding stages, is more favorable as the energy availability from feed converted into fat-body reserves is higher (Fig. 4). The ratio between energy invested and energy spent is higher than 1.0 in the $\mathrm{ED}_{4}$ which indicates that the heaviest individuals invested a higher amount of energy in clutch quality than in post-feeding processes (Fig. 4).

\section{Effect of the energy content of the diets on fat storage and fatty acid profiles of larvae}

The results show that the amount of fat in 10 day-old larvae of Hermetia illucens is strongly associated with the energy content of their diets $(r=0.976)$ (Table 5). The feed energy accumulation in the form of lipid tissue was previously reported by Barragan-Fonseca et al. (2018) for larvae reared on diets with different energy contents. Our results are in the range reported in the literature review (7-39\% of DM) of Barragan-Fonseca et al. (2017), which also highlights the influence of the rearing diets on larval development.

The fat content of 20 day-old larvae (Fig. 2) is also strongly associated with the energy content of their diets $(r=0.986)$ (Table 5). Usually, rearing on substrates with high fat and carbohydrate contents are associated with high concentrations of fat in larvae (Zheng et al., 2012). Therefore, the high fat content of larvae reared on the $\mathrm{ED}_{4}$ diet may be due to a high utilization of carbohydrates (Arrese $\&$ Soulages, 2010; Meneguz et al., 2018), as insects can convert carbohydrates into lipids (Inagaki \& Yamashita, 1986; Spranghers et al., 2017). The purpose of converting carbohydrates into body lipids is primarily to provide an energy source for adults (Tomberlin \& Sheppard, 2002; Hoc et al., 2020) and secondly it decreases the evapotranspiration from larvae because of their high body surface to volume ratio (Downer \& Matthews, 1976). This may account for the higher larval growth recorded on diets with the highest energy contents and indicate that the metabolism of the larvae of Hermetia illucens is especially adapted to converting the energy in their food into biomass, especially in the form of fat (lipid reserves). This is also suggested by Oonincx et al. (2015), based on the rapid development of larvae (in 21 days) when the substate they fed on included a high amount of fat (9.5\%). Barragan-Fonseca et al. (2019) also report that larval yield is higher on diets with a high carbohydrate content $(55 \%)$ and the larvae contain high amounts of fat. Li et al. (2015) report that the addition of high energy ingredients (such as glucose and xylose) to the rearing substrate results in an increase in fat body content of the larvae up to a maximum of $34 \%$ of DM. Cammack \& Tomberlin (2017) report accelerated development of larvae of Hermetia illucens, associated with a lower food intake, if the ratio of protein to carbohydrates in the diet is $1: 1$. Similary, the accumulation of fat by the larvae of Hermetia illucens, which is used by the no-feeding stages, is also reported by Spranghers et al. (2017), who report a fat content of $37.1 \%$ of DM in prepupae. Caligiani et al. (2018) report a fat content of $34.1 \%$ of DM using similar rearing substrates.

Our results are in accordance with those in the literature and the very similar fat content of $37.36 \%$ of DM reported by Jucker et al. (2020) for larvae reared on a diet of fruit and vegetables, which is higher than the $32.97 \%$ of DM reported by Gianetto et al. (2020) for larvae reared on the same type of substrate. Our values and those of the authors cited are within the limits of the fat contents reported by Scala et al. (2020), which are between $20.1-36.1 \%$ for larvae reared on a fruit and vegetable substrate. On the standard diet, the larval fat values are similar to those reported by Danieli et al. (2019) for prepupae (33.0\% of DM). Pamintuan et al. (2019) report higher values (40.55\%) for larvae reared on a waste vegetable substrate.

The fatty acids profiles of the fat in larvae, prepupae and pupae is strongly associated with the nature of the larval rearing substrate (Barragan-Fonseca et al., 2017; Smets et al., 2020). Some of the nutrients in the substrates are assimilated by larvae (Ewald et al., 2020) and are present in the prepupae and pupae (Smets et al., 2020). Therefore, the nutritive reserves accummulated by the larvae are the resource that ensure the successful development of the non feeding stages.

The fat profile of Hermetia illucens larvae is characterized by a high percentage of saturated fatty acids (60-70\% of FAME) and lower percentage of unsaturated fatty acids (30-40\%) (Barragan-Fonseca et al., 2018; Gianetto et al., 2020; Hoc et al., 2020; Jucker et al., 2020; Saadoun et al., 2020). In the present research, this was also recorded for the fats in larvae reared on the control diet $(56.05 \%$ saturated fatty acids and $43.95 \%$ unsaturated fatty acids). This is similar to that reported by Jucker et al. (2020) for larvae reared on the standard diet $(60.1 \%$ SFA and $30.0 \%$ UFA). On this diet, similar results to those of Saadoun et al. (2020) were recorded for MUFA (131.36 vs $131.8 \mathrm{mg} / \mathrm{g}$ ). Approximately equal percentages of SFA and UFA were recorded for $\mathrm{ED}_{4}(50.86 \%$ saturated fatty acids and $49.14 \%$ 
unsaturated fatty acids), which is in accordance with that reported by Jucker et al. (2017), who obtained a higher level of SFA than UFA in larvae reared on the same type of substrate. Similar results to those presented here are reported by Meneguz et al. (2018) for SFA (212.6 vs 220.6 $\mathrm{mg} / \mathrm{g})$ and oleic acid (74.37 vs $65.9 \mathrm{mg} / \mathrm{g})$.

In the larvae reared on the $\mathrm{ED}_{1}-\mathrm{ED}_{3}$ diets, in which the soybean meal was rich in unsaturated fatty acids, there was a similarly high level of unsaturated fatty acids (Table 3 ). The concentrations of unsaturated fatty acids in the fat of larvae reared on these diets was higher than that of the saturated fatty acids, being between $55-58 \%$. This is supported by the high UFA/SFA values (1.23-1.36) recorded for these larvae (Table 3). Jucker et al. (2017) report lower PUFA/SFA values for larvae $(0.37$ vs 0.46$)$ reared on a diet of fruit and vegetables. Among the PUFAs, the predominant acid is linoleic acid, which was previously reported by Barroso et al. (2017) and Liland et al. (2017) (11.8$55.9 \%)$. Among the MUFAs, the most abundant were palmitoleic and oleic acids, which is in accordance with the results of the previously cited authors. Moreover, Hoc et al. (2020) report that the structure of larval fats and that of the prepupa in terms of the fatty acid profile are the same. These results clearly indicate that the composition of the diets directly influenced the chemical composition of the larvae of Hermetia illucens and the nutritional quality of their fats, in terms of fatty acid content.

\section{Effect of the energy content of the diets on the quality of egg clutches}

The quality of the egg clutches is significantly associated $(\mathrm{p}<0.01)$ with the energy content of the diet the larvae were reared on (Table 4). For $\mathrm{ED}_{3}$ which has a high energy content, the average weight of a clutch of eggs and number of eggs in a clutch were significantly higher $(p<0.05)$ than for the control diet. In addition, associated with the high energy content of the fruit and vegetable diet $\left(\mathrm{ED}_{4}\right)$ were significantly higher $(p<0.01)$ weights of the clutches of eggs and number of eggs than for all the other diets. That is, the energy reserves accumulated by the actively feeding larvae clearly influenced the quality of the eggs.

Bertinetti et al. (2019) report that the average weight of a clutch of eggs of $H$. illucens is $27.10 \mathrm{mg}$, when reared on a substrate composed of wheat bran $(75 \%)$ and poultry feed $(25 \%)$, being higher than those obtained by us in group $\mathrm{ED}_{3}(23.93 \mathrm{mg})$, but lower than that for $\mathrm{ED}_{4}$ (31.75). The average weight of a clutch of eggs recorded for the control diet $(18.54 \mathrm{mg})$ is higher than that reported by Tomberlin \& Sheppard (2002) for H. illucens reared on the same substrate $(14.5 \mathrm{mg})$. The average number of eggs laid by females reared on $\mathrm{CD}-\mathrm{ED}_{3}$ diets, are higher than those previously reported by Barros et al. (2019) (620-700 eggs), but comparable with those reported by Kim et al. (2008) (1001 \pm 247 eggs) and Bertinetti et al. (2019) (1060 eggs).

The present research does not reveal an obvious effect of the energy content of the diet in terms of the UFA/SFA value on the quality of eggs (weight and number of eggs/ clutch). However, it should be noted that the clutches laid by $H$. illucens reared on $\mathrm{ED}_{4}$, were of high quality and associated with approximately equal amounts of UFA and SFA (0.97).

In conclusion, the energy content of the rearing substrate directly influences larval body weight and indirectly that of the no-feeding stages. The larval body fat reserves are strongly correlated with the energy contens of the substrates. The quality of the fats in the rearing substrate influences the fatty acid profile of the fat stored by larvae. The energy stored in the fat-body directly influences the quality of the egg clutches.

\section{REFERENCES}

ArRese E.L. \& Soulages J.L. 2010: Insect fat body: energy, metabolism, and regulation. - Annu. Rev. Entomol. 55: 207-225.

BANKS I., GiBson W. \& CAMERON M. 2014: Growth rates of black soldier fly larvae fed on fresh human faeces and their implication for improving sanitation. - Trop. Med. Int. Health 19: $14-22$.

BarRagan-Fonseca K.B., Dicke M. \& van LoOn J.J.A. 2017: Nutritional value of the black soldier fly (Hermetia illucens L.) and its suitability as animal feed - a review. - J. Insects Food Feed. 3: 105-120.

Barragan-Fonseca K.B., Dicke M. \& van Loon J.J. 2018: Influence of larval density and dietary nutrient concentration on performance, body protein, and fat contents of black soldier fly larvae (Hermetia illucens). - Entomol. Exp. Appl. 166: 761-770.

Barragan-Fonseca K.B., Gort G., Dicke M. \& van Loon J.J.A. 2019: Effects of dietary protein and carbohydrate on life-history traits and body protein and fat contents of the black soldier fly Hermetia illucens. - Physiol. Entomol. 44: 148-159.

Barros L.M., Gutjahr A.L.N., Ferreira-Keppler R.L. \& MarTINS R.T. 2019: Morphological description of the immature stages of Hermetia illucens (Linnaeus, 1758) (Diptera: Stratiomyidae). - Microsc. Res. Tech. 82: 178-189.

Barroso F.G., Sánchez-Muros M.J., Segura M., Morote E., Torres A., Ramos R. \& Guil J.L. 2017: Insects as food: Enrichment of larvae of Hermetia illucens with omega 3 fatty acids by means of dietary modifications. - J. Food Compos. Anal. 62: 8-13.

Bava L., Jucker C., Gislon G., Lupi D., Savoldelli S., Zucali M. \& Colombini S. 2019: Rearing of Hermetia illucens on different organic by-products: influence on growth, waste reduction, and environmental impact. - Animals 9(6): 289, 16 pp.

Bertinetti C., Samayoa A.C. \& Hwang S.Y. 2019: Effects of feeding adults of Hermetia illucens (Diptera: Stratiomyidae) on longevity, oviposition, and egg hatchability: insights into optimizing egg production. - J. Insect Sci. 19(1): 19, 7 pp.

Boaru A., Vig A., Ladoși D., Struți D., Păpuc T. \& Georgescu B. 2018: Studies regarding the fertilizing capacity of poultry manure biocomposted by fly larvae (Diptera: Stratiomyidae). - AAB Bioflux. 10: 114-121.

Boaru A., Vig A., Ladoși D., Păpuc T., Struți D. \& Georgescu B. 2019: The use of various oviposition structures for the black soldier fly, Hermetia illucens L. (Diptera: Stratiomydae) in improving the reproductive process in captivity. - ABAH Bioflux. 11: 12-20.

Bruno D., Bonelli M., Cadamuro A.G., Reguzzoni M., Grimaldi A., Casartelli M. \& Tettamanti G. 2019: The digestive system of the adult Hermetia illucens (Diptera: Stratiomyidae): morphological features and functional properties. - Cell Tissue Res. 378: 221-238. 
Caligiani A., Marseglia A., Leni G., Baldassarre S., Maistrello L., Dossena A. \& Sforza S. 2018: Composition of black soldier fly prepupae and systematic approaches for extraction and fractionation of proteins, lipids and chitin. - Int. Food Res. J. 105: 812-820.

Cammack J.A. \& Tomberlin J.K. 2017: The impact of diet protein and carbohydrate on select life-history traits of the black soldier fly Hermetia illucens (L.) (Diptera: Stratiomyidae). Insects 8(2): 56, 14 pp.

ČıčKová H., Newton G.L., Lacy R.C. \& KozÁnek M. 2015: The use of fly larvae for organic waste treatment. - Waste Manag. 35: $68-80$.

Cullere M., Schiavone A., Dabbou S., Gasco L. \& Dalle Z.A. 2019: Meat quality and sensory traits of finisher broiler chickens fed with black soldier fly (Hermetia illucens L.) larvae fat as alternative fat source. - Animals 9(4): 140, 15 pp.

Danieli P.P., Lussiana C., Gasco L., Amici A. \& Ronchi B. 2019 : The effects of diet formulation on the yield, proximate composition, and fatty acid profile of the black soldier fly (Hermetia illucens L.) prepupae intended for animal feed. - Animals 9(4): $178,20 \mathrm{pp}$.

Downer R.G.H. \& Matthews J.R. 1976: Patterns of lipid distribution and utilisation in insects. - Am. Zool. 16: 733-745.

Ewald N., Vidakovic A., Langeland M., Kiessling A., Sampels S. \& LALANDER C. 2020: Fatty acid composition of black soldier fly larvae (Hermetia illucens) - Possibilities and limitations for modification through diet. - Waste Manag. 102: 40-47.

Georgescu B., Struți D., Păpuc T., Ladoși D. \& Boaru A. 2020 Body weight loss of black soldier fly Hermetia illucens (Diptera: Stratiomyidae) during development in non-feeding stages: Implications for egg clutch parameters. - Eur. J. Entomol. 117: $216-225$.

Giannetto A., Oliva S., Ceccon Lanes C.F., de Araujo P.F., Savastano D., Baviera C., Parrino V., Lo Paro G., Spano N.C., Cappello T., Maisano M., Mauceri A. \& Fasulo S. 2020: Hermetia illucens (Diptera: Stratiomydae) larvae and prepupae: biomass production, fatty acid profile and expression of key genes involved in lipid metabolism. - J. Biotechnol. 307: 44-54.

Gobbi P., Martinez-SAnchez A. \& Rojo S. 2013: The effects of larval diet on adult life-history traits of the black soldier fly, Hermetia illucens (Diptera: Stratiomyidae). — Eur. J. Entomol. 110: 461-468.

HaRnden L.M. \& TomberLin J.K. 2016: Effects of temperature and diet on black soldier fly, Hermetia illucens (L.) (Diptera: Stratiomyidae), development. — Forensic Sci. Int. 266: 109116.

Heussler C.D., Walter A., Oberkofler H., Insam H., Arthofer W., Schlick-Steiner B.C. \& Steiner F.M. 2018: Influence of three artificial light sources on oviposition and half-life of the black soldier fly, Hermetia illucens (Diptera: Stratiomyidae): Improving small-scale indoor rearing. - PLOS ONE 13(5): e0197896, $10 \mathrm{pp}$.

Hoc B., Noël G., Carpentier J., Francis F. \& Caparros M.R. 2019: Optimization of black soldier fly (Hermetia illucens) artificial reproduction. - PLOS ONE 14(4): e 0216160, 13 pp.

Hoc B., Genva M., Fauconnier M.L., Lognay G., Francis F. \& Megido R.C. 2020: About lipid metabolism in Hermetia illucens (L. 1758): on the origin of fatty acids in prepupae. - Sci. Rep. 10(1): 11916, 9 pp.

Hogsette J.A. 1992: New diets for production of house flies and stable flies (Diptera: Muscidae) in the laboratory. $-J$. Econ. Entomol. 85: 2291-2294.
Holmes L.A., Vanlaerhoven S.L. \& Tomberlin J.K. 2012: Relative humidity effects on the life history of Hermetia illucens (Diptera: Stratiomyidae). — Environ. Entomol. 41: 971-978.

INAGAKI S. \& YAMASHITA O. 1986: Metabolic shift from lipogenesis to glycogenesis in the last instar larval fat body of the silkworm, Bombyx mori. - Insect Biochem. 16: 327-331.

Jucker C., Erba D., Leonardi M.G., Lupi D. \& Savoldelli S. 2017: Assessment of vegetable and fruit substrates as potential rearing media for Hermetia illucens (Diptera: Stratiomyidae) larvae. - Environ. Entomol. 46: 1415-1423.

Jucker C., Leonardi M., Rigamonti I., Lupi D. \& Savoldelli S. 2019: Brewery's waste streams as a valuable substrate for Black Soldier Fly Hermetia illucens (Diptera: Stratiomyidae). - J. Entomol. Acarol. Res. 51: 87-94.

Jucker C., Lupi D., Moore C.D., Leonardi M.G. \& Savoldelli S. 2020: Nutrient recapture from insect farm waste: bioconversion with Hermetia illucens (L.) (Diptera: Stratiomyidae). Sustainability 12(1): 362, 14 pp.

Kim J.G., Choi Y.C., Choi J.Y., Kim W.T., Jeong G.S., Park K.H. \& Hwang S.J. 2008: Ecology of the Black Soldier Fly, Hermetia illucens (Diptera: Stratiomyidae) in Korea. - Kor. J. Appl. Entomol. 47: 337-343.

Kroeckel S., Harjes A.G.E., Roth I., Katz H., Wuertz S., SusenBETH A. \& SCHULz C. 2012: When a turbot catches a fly: evaluation of a pre-pupae meal of the black soldier fly (Hermetia illucens) as fish meal substitute - Growth performance and chitin degradation in juvenile turbot (Psetta maxima). - Aquacult. Fish. Manag. 364: 345-352.

Lalander C., Senecal J., Gros C.M., Ahrens L, Josefsson S., WibERG K. \& VinNERÅs B. 2016: Fate of pharmaceuticals and pesticides in fly larvae composting. - Sci. Total Environ. 565: 279-286.

Li Q., Zheng L., Cai H., Garza E., Yu Z. \& Zhou S. 2011: From organic waste to biodiesel: Black soldier fly, Hermetia illucens, makes it feasible. - Fuel 90: 1545-1548.

Li W., Li M., Zheng L., Liu Y., Zhang Y., Yu Z., Zonghua M. \& LI Q. 2015: Simultaneous utilization of glucose and xylose for lipid accumulation in black soldier fly. - Biotechnol. Biofuels 8(1): 117,6 pp.

Liland N.S., Biancarosa I., Araujo P., Biemans D., Bruckner C.G., Waagbø R., Torstensen B.E. \& Lock E.J. 2017: Modulation of nutrient composition of black soldier fly (Hermetia illucens) larvae by feeding seaweed-enriched media. - PLOS ONE 12(8): e0183188, 23 pp.

Liu X., Chen X., Wang H., Yang Q., ur Rehman K., Li W., Cai M., Li Q., Mazza L., Zhang J., Yu Z. \& Zheng L. 2017: Dynamic changes of nutrient composition throughout the entire life cycle of black soldier fly. - PLOS ONE 12(8): e0182601, $21 \mathrm{pp}$.

Magalhães R., Sánchez-López A., Leal R.S., Martínez-Llorens S., Oliva-Teles A. \& Peres H. 2017: Black soldier fly (Hermetia illucens) pre-pupae meal as a fish meal replacement in diets for European seabass (Dicentrarchus labrax). - Aquaculture 476: 79-85.

Makkar H.P.S., Tran G., HeuzÉ V. \& AnKers P. 2014: State-ofthe-art on use of insects as animal feed. - Anim. Feed Sci. Tech. 197: 1-33.

Meneguz M., Schiavone A., Gai F., Dama A., Lussiana C., Renna M. \& GASCO L. 2018: Effect of rearing substrate on growth performance, waste reduction efficiency and chemical composition of black soldier fly (Hermetia illucens) larvae. - J. Sci. Food Agric. 98: 5776-5784.

Miranda C.D., CAmmack J.A. \& Tomberlin J.K. 2019: Life-history traits of the black soldier fly, Hermetia illucens (L.) (Di- 
ptera: Stratiomyidae), reared on three manure types. - Animals 9(5): 281, $15 \mathrm{pp}$.

Miranda C.D., Cammack J.A. \& Tomberlin J.K. 2020: Mass production of the black soldier fly, Hermetia illucens (L.), (Diptera: Stratiomyidae) reared on three manure types. - Animals 10(7): 1243, $11 \mathrm{pp}$

Nakamura S., ICHIKI R.T., Shimoda M. \& Morioka S. 2016: Small-scale rearing of the black soldier fly, Hermetia illucens (Diptera: Stratiomyidae), in the laboratory: low-cost and yearround rearing. - Appl. Entomol. Zool. 51: 161-166.

Nguyen T.T.X., Tomberlin J.K. \& Vanlaerhoven S. 2013: Influence of resources on Hermetia illucens (Diptera: Stratiomyidae) larval development. - J. Med. Entomol. 50: 898-906.

Nguyen T.T.X., Tomberlin J.K. \& Vanlaerhoven S. 2015: Ability of black soldier fly (Diptera: Stratiomyidae) larvae to recycle food waste. - Environ. Entomol. 44: 406-410.

OONINCX D., van HuIs A. \& van LoON J. 2015: Nutrient utilization by black soldier flies fed with chicken, pig, or cow manure. J. Insects Food Feed. 1: 131-139.

Pamintuan K.R.S., Cajayon J.A.B. \& Dableo G.B. 2019: Growth characteristics and lipid content of black soldier fly (Hermetia illucens) larva reared in milkfish offal and mixed vegetable wastes. In: Proceedings of the 6th International Conference on Biomedical and Bioinformatics Engineering, Shanghai, China, November 13-15, 2019. Association for Computing Machinery, New York, NY, pp. 163-168.

Park K.H., Kim W.T., Lee S.B., Choi Y.C. \& Nho S. 2010: Seasonal pupation, adult emergence and mating of black soldier fly, Hermetia illucens (Diptera: Stratiomyidae) in artificial rearing system. — Int. J. Indust. Entomol. 21: 189-191.

Pimentel A.C., Montali A., Bruno D. \& Tettamanti G. 2017 Metabolic adjustment of the larval fat body in Hermetia illucens to dietary conditions. - J. Asia Pac. Entomol. 20: 13071313.

Ramos-Bueno R.P., GonzÁlez-Fernández M.J., SÁncheZ-MurosLozano M.J., García-Barroso F. \& Guil-Guerrero J.L. 2016 Fatty acid profiles and cholesterol content of seven insect species assessed by several extraction systems. - Eur. Food Res. 242: 1471-1477.

Renna M., Schiavone A., Gai F., Dabbou S., Lussiana C., Malfatto V., Prearo M., Capucchio M.T., Biasato I., Biasibetti E., De Marco M., Brugiapaglia A., Zoccarato I. \& Gasco L. 2017: Evaluation of the suitability of a partially defatted black soldier fly (Hermetia illucens L.) larvae meal as ingredient for rainbow trout (Oncorhynchus mykiss Walbaum) diets. $-J$. Anim. Sci. Biotechnol. 8(1): 57, 13 pp.

SaAdoun J.H, Montevecchi G., Zanasi L., Bortolini S., Macavei L.I., Masino F., Maistrello L. \& Antonelli A. 2020: Lipid profile and growth of black soldier flies (Hermetia illucens, Stratiomyidae) reared on by-products from different food chains. - J. Sci. Food Agric. 100: 3648-3657.

Salomone R., Saija G., Mondello G., Giannetto A., Fasulo S. \& SaVASTANo D. 2017: Environmental impact of food waste bioconversion by insects: Application of life cycle assessment to process using Hermetia illucens. - J. Clean. Prod. 140: 890-905

Scala A., Cammack J.A., Salvia R., Scieuzo C., Franco A., Bufo S.A., Tomberlin J.K. \& Falabellaet P. 2020: Rearing substrate impacts growth and macronutrient composition of Her- metia illucens (L.) (Diptera: Stratiomyidae) larvae produced at an industrial scale. - Sci. Rep. 10: 19448, 8 pp.

Sheppard D.C., Tomberlin J.K., Joyce J.A., Kiser B.C. \& Sumner S.M. 2002: Rearing methods for the black soldier fly (Diptera: Stratiomyidae). - J. Med. Entomol. 39: 695-698.

Smets R., Verbinnen B., Van De Voorde I., Aerts G., Claes J. \& VAN DeR Borght M. 2020: Sequential extraction and characterisation of lipids, proteins, and chitin from black soldier fly (Hermetia illucens) larvae, prepupae, and pupae. - Waste Biomass Valor. 11: 6455-6466.

Spranghers T., Ottoboni M., Klootwijk C., Ovyn A., Deboosere S., Meulenaer B.D., Michiels J., Eeckhout M., Clerce P.D. \& SMET S.D. 2017: Nutritional composition of black soldier fly (Hermetia illucens) prepupae reared on different organic waste substrates. - J. Sci. Food. Agric. 97: 2594-2600.

SRIKANTH B. \& Sharanabasappa D. 2021: Growth performance and bioconversion rate of black soldier fly Hermetia illucens (L.). — Indian J. Entomol. 83: e20310, 4 pp.

St-Hilaire S., Sheppard C., Tomberlin J., Irving S., Newton L., McGuire M., Mosley E., Hardy R. \& Sealey W. 2007: Fly prepupae as a feedstuff for rainbow trout, Oncorhynchus mykiss. - J. World Aquacult. Soc. 38: 59-67.

Surendra K.C., Olivier R., Tomberlin J.K., Jha R. \& Khanal S.K. 2016: Bioconversion of organic wastes into biodiesel and animal feed via insect farming. - Renew. Energy 98: 197-202.

TOMBERLIN J.K. \& SHePPARD D.C. 2002: Factors influencing mating and oviposition of black soldier flies (Diptera: Stratiomyidae) in a colony. - J. Entomol. Sci. 37: 345-352.

Tomberlin J.K., Adler P.H. \& Myers H.M. 2009: Development of the black soldier fly (Diptera: Stratiomyidae) in relation to temperature. - Environ. Entomol. 38: 930-934.

Truzzi C., Giorgini E., Annibaldi A., Antonucci M., Illuminati S., Scarponi G., Paola R., Nunzio I., Carla C., Matteo Z., Renato C. \& Ike O. 2020: Fatty acids profile of black soldier fly (Hermetia illucens): Influence of feeding substrate based on coffee-waste silverskin enriched with microalgae. - Anim. Feed Sci. Tech. 259: 114309, 21 pp.

Ushakova N.A., Brodski E.S., KovalenKo A.A., Bastrakov A.I., Kozlova A.A. \& Pavlov D.S. 2016: Characteristics of lipid fractions of larvae of the black soldier fly Hermetia illucens. Dokl. Biochem. Biophys. 468: 209-212.

VeldKAMP T. \& Bosch G. 2015: Insects: a protein-rich feed ingredient in pig and poultry diets. - Anim. Front. 5: 45-50.

WANG Y.S. \& SheLomi M. 2017: Review of black soldier fly (Hermetia illucens) as animal feed and human food. - Foods 6(10): 91, 23 pp.

Zheng L., Li Q., Zhang J. \& Yu Z. 2012: Double the biodiesel yield: Rearing black soldier fly larvae, Hermetia illucens, on solid residual fraction of restaurant waste after grease extraction for biodiesel production. - Renew. Energy 41: 75-79.

Zhu Z., uR Rehman K., Yu Y., Liu X., Wang H., Tomberlin J.K., Sze S.H., Cal M., Zhang J., Yu Z. \& Zheng L. 2019: De novo transcriptome sequencing and analysis revealed the molecular basis of rapid fat accumulation by black soldier fly (Hermetia illucens, L.) for development of insectival biodiesel. - Biotechnol. Biofuels 12(1): 194, 16 pp.

Received July 15, 2021; revised and accepted August 29, 2021 Published online October 5, 2021 